\title{
Calpain-mediated pathway dominates cisplatin-induced apoptosis in human lung adenocarcinoma cells as determined by real-time single cell analysis
}

\author{
Lei Liu', Da Xing ${ }^{1 *}$, Wei R. Chen ${ }^{1,2}$, Tongsheng Chen ${ }^{1}$, Yihui Pei ${ }^{1}$ and Xuejuan Gao ${ }^{1}$ \\ ${ }^{1}$ MOE Key Laboratory of Laser Life Science and Institute of Laser Life Science, South China Normal University, \\ Guangzhou 510631, China \\ ${ }^{2}$ Biomedical Engineering Program, Department of Engineering and Physics, College of Mathematics and Science, \\ University of Central Oklahoma, Edmond, OK 73034
}

\begin{abstract}
Cisplatin is an efficient anticancer agent. Cisplatin-based chemotherapy is believed to involve different signal transduction pathways, among which calpain activation has been proposed as an important factor in the induced apoptosis. In our study, based on real-time single cell analysis, we investigated the molecular involvement of calpain in cisplatin-induced apoptosis in living human lung adenocarcinoma cells. After cisplatin treatment, calpain was activated, resulting in Bid cleavage at 4-5 hr, followed by Bid translocation and cytochrome $c$ release, leading to cell death. Calpeptin and PD150606, specific inhibitors of calpain, blocked Bid activation completely; however, cytochrome $c$ release was delayed by more than $2 \mathrm{hr}$, which was associated with the delay of caspase-3 activation and cell death. Remarkably, calpainmediated release of cytochrome $c$ and cell death was significantly compromised in the Bid knockdown cells. Z-IETD-fmk and ZVDVAD-fmk were used to block the activation of caspase-8 and caspase-2, respectively; however, the progression of apoptosis were not affected, suggesting that caspase-8 and caspase-2 were not involved in this experimental model. Taken together, the data demonstrate that calpain mediated cisplatin-induced apoptosis in human lung adenocarcinoma cells through activating Bid, which then regulated the mitochondrial apoptotic pathway. The delays of cytochrome $c$ release, caspase- 3 activation and subsequent cell death by inactivating calpain or silencing Bid exclude other earlier or parallel pathways, strongly suggesting that the calpain-mediated pathway is the kinetically earliest one, which dominates the cisplatin-induced apoptosis.

(C) 2008 Wiley-Liss, Inc.
\end{abstract}

Key words: cisplatin; calpain; apoptosis; Bid; caspase-8

Cisplatin (cis-diammine dichloroplatinum; cis-Platinum(II)) is a potent anticancer drug for the treatment of various malignancies. ${ }^{1,2}$ The cytotoxicity of cisplatin results from the formation of DNA adducts, which include interstrand and intrastrand DNA cross-links, DNA-protein cross-links and DNA monoadducts. ${ }^{1,2}$ Cisplatin is recognized as a DNA-damaging agent. Yet the mechanism whereby DNA damage kills cells is not fully understood. Inhibition of DNA synthesis was initially considered to be the main cause of cisplatin's cytotoxicity. However, recent studies demonstrate that besides inhibition of DNA replication, cisplatin treatment also affects other fundamental cellular processes, including RNA transcription, protein translation, DNA repair, cell cycle and apoptosis. ${ }^{1-3}$ Considerable evidence has indicated that cisplatin can kill cells through the induction of apoptosis. However, it is not well known how cellular signaling from drug-induced DNA lesions leads to the execution-phase characteristics of apoptosis.

Two cytosolic proteolytic systems, caspase and calpain, are capable of producing limited cleavage of endogenous proteins. Calpain is a ubiquitous cysteine protease. Although it is well established that several members of the caspase family are involved in apoptosis, ${ }^{4,5}$ the physiological role of calpain in apoptosis is much less clear. ${ }^{6}$ Ablation of the common noncatalytic $30-\mathrm{kDa}$ subunit of calpain causes embryonic lethality in mice, pointing to the essential role of the enzyme. ${ }^{7}$ A number of studies have shown that calpain activation precedes cell death induced by different apoptotic stimuli in various cell systems. ${ }^{8,9}$ The potential role of calpain in apoptosis is also indicated by the growing list of calpain substrates, including p53, PARP, Bid and several cytoskeletal pro- teins. ${ }^{10,11}$ Currently, the contribution of calpain to apoptosis is generally accepted, though its exact role remains unclear.

Two major distinct apoptosis pathways have been described for mammalian cells. One involves caspase-8, which is recruited by the adapter molecule Fas/APO-1-associated death domain protein to death receptors upon extracellular ligand binding. ${ }^{12,13}$ The other is the mitochondrial apoptotic pathway, involving $\mathrm{Bcl}-2$ family members, cytochrome $c$ and caspase-9. ${ }^{14-16}$ Several studies have suggested that caspase- 8 is involved in cisplatin-induced apoptosis. ${ }^{17,18}$ However, Wang et al. found that cisplatin could induce apoptosis without activation of caspase-8. ${ }^{1,19,20}$ The debate over the involvement of caspase- 8 activation in cisplatininduced apoptosis continues.

Bid, a member of the BH3-only subgroup of the Bcl-2 family, is a unique proapoptotic protein. ${ }^{21} \mathrm{BH} 3$-only proteins are implicated as essential regulators of apoptosis. ${ }^{22,23}$ Bid plays an essential role in apoptotic signaling, by inducing the proapoptotic functionality of Bak and Bax, leading to cytochrome $c$ release. ${ }^{24} \mathrm{Bid}$ is normally localized in the cytosol in an inactive form. Activation of Bid depends on the cleavage of intact Bid into its truncated form of tBid. The resulting tBid then translocates into mitochondria and leads to disruption of organelles and release of apoptogenic molecules such as cytochrome $c .^{13,25,26}$ The cleavage of Bid can be conducted by several proteases. Caspase- 8 has been shown to be the protease most responsible for Bid cleavage during death receptor-mediated apoptosis. ${ }^{25}$ Calpain has also been shown to cleave Bid. ${ }^{11,27,28}$ Other studies have demonstrated that Bid can also be cleaved by caspase- 3 and caspase- 2 in the intrinsic pathway to apoptosis, which is independent of death receptors. 29,36

Fluorescence resonance energy transfer (FRET) is a nonradiative transfer of energy between 2 fluorophores that are placed in close vicinity and in a proper relative angular orientation, which can spatio-temporally monitor cell events in physiological condition in single living cell. ${ }^{31,32}$ It has been utilized to reveal the dynamic activity of enzyme, and it provides a view of protein location, protein translocation, small ligand binding, protein-protein interaction, conformational change and posttranslational modification in real-time. ${ }^{33-36}$ This can not be fully elucidated by traditional biophysical or biochemical approaches, which can only measure the average behavior of cell populations and the static

Abbreviations: Calpain, calcium-activated proteinase; CCK-8, cell counting kit-8; CFP, cyan fluorescent protein; Cyt- $c$, cytochrome $c$; ERK, extracellular signal-regulated kinase; FRET, fluorescence resonance energy transfer; GFP, green fluorescent protein; IAP, inhibitor of apoptosis; NC, negative control; RNAi, RNA interference; shRNA, short hairpin RNA; YFP, yellow fluorescent protein.

Grant sponsor: National Natural Science Foundation of China; Grant numbers: 30600128, 30470494; Grant sponsor: Natural Science Foundation of Guangdong Province; Grant number: 7117865; Grant sponsor: US National Institute of Health; Grant number: P20 RR016478.

*Correspondence to: MOE Key Laboratory of Laser Life Science and Institute of Laser Life Science, South China Normal University, Guangzhou 510631, China. E-mail: xingda@scnu.edu.cn

Received 8 October 2007; Accepted after revision 26 November 2007 DOI 10.1002/ijc. 23378

Published online 23 January 2008 in Wiley InterScience (www.interscience. wiley.com). 
spatial information available from fixed cells and thus can not provide direct access to cells life event in their natural environment.

Given these backgrounds, it is of importance to determine the effect of calpain activation in cell apoptosis, particularly induced by chemotherapeutic agent such as cisplatin. To determine the molecular involvement of calpain in cisplatin-induced apoptosis in living human lung adenocarcinoma cells, our study focuses on (i) calpain activation and its contribution in the apoptotic pathway, (ii) the dynamic process of cell apoptosis, including Bid activation, Bid translocation, cytochrome $c$ release, (iii) the role of caspase-2, -3 and -8 in cell apoptosis and (iv) the dominant apoptotic pathway in this experimental model.

\section{Material and Methods}

\section{Cell culture, transfection and treatment}

The human lung adenocarcinoma cell lines ASTC-a-1 and A549 were obtained from the Department of Medicine, Jinan University (Guangzhou, China) and cultured in DMEM (GIBCO, Grand Island, NY) supplemented with $15 \%$ fetal calf serum (FCS), penicillin (100 units $/ \mathrm{ml})$ and streptomycin $(100 \mathrm{mg} / \mathrm{ml})$ in $5 \% \mathrm{CO}_{2}$ at $37^{\circ} \mathrm{C}$ in a humidified incubator. Transfections were performed with Lipofectamine ${ }^{\mathrm{TM}}$ reagent (Invitrogen, Carlsbad, CA) according to the manufacturer's protocol. The solution of Lipofectamine $^{\mathrm{TM}}$ reagent was replaced with fresh culture medium after $5 \mathrm{hr}$. Cells were examined $36 \mathrm{hr}$ after transfection. To obtain stable cell lines expressing YFP-Bid-CFP, transfected cells were selected in the presence of $0.8 \mathrm{mg} / \mathrm{ml} \mathrm{G} 418$ for 2 weeks and fluorescent clones were enriched.

The concentration of cisplatin (Sigma-Aldrich, St. Louis, MO) used in our experiments was $20 \mu \mathrm{M}$. In the experiments using calpeptin $(10 \mu \mathrm{M})$ (Alexis Biochemicals, Coger, Paris, France), PD150606 $(20 \mu \mathrm{M})$ (Alexis Biochemicals, Coger, Paris, France), Z-VDVAD-fmk $(100 \mu \mathrm{M})$, Z-IETD-fmk $(10 \mu \mathrm{M})$, Z-DEVD-fmk $(25 \mu \mathrm{M})$ (BioVision, Mountain View, CA) and Z-VAD-fmk $(25 \mu \mathrm{M})$ (Sigma-Aldrich, St. Louis, MO), all the chemicals were added to the cells 30 min before cisplatin.

\section{Time-lapse confocal fluorescence microscopy}

GFP, CFP and DsRed emissions were monitored confocally using a laser scanning microscope (LSM 510/ConfoCor 2) combination system (Zeiss, Jena, Germany) equipped with a PlanNeofluar $40 \times / 1.3$ NA Oil DIC objective. Excitation wavelength and detection filter settings for each of the fluorescent indicators were as follows. GFP was excited at $488 \mathrm{~nm}$ with an argon ion laser and its fluorescence emission was recorded through a 500$530 \mathrm{~nm}$ IR band-pass filter. CFP was excited at $458 \mathrm{~nm}$ with an argon ion laser and its fluorescence emission was recorded through a $470-500 \mathrm{~nm}$ band-pass filter. DsRed was excited at $543 \mathrm{~nm}$ with a helium-neon laser and its emitted light was recorded through a 560-nm long-pass filter.

For time-lapse imaging, culture dishes were mounted onto the microscope stage equipped with a temperature-controlled chamber (Zeiss, Jena, Germany).

\section{FRET analysis of Bid cleavage kinetics}

FRET is a powerful tool for investigation of molecular events in living cells. In our study, a fusion protein pFRET-Bid (pYFPBid-CFP) has been used to observe the cleavage of Bid and to detect the activity of calpain in cisplatin-induced apoptosis. It is constructed by connecting a yellow fluorescent protein (YFP) and a cyan fluorescent protein (CFP) to the $\mathrm{N}$ terminus and the $\mathrm{C}$ terminus of Bid, respectively. ${ }^{33}$ For excitation, the $458-\mathrm{nm}$ line of an Ar-Ion Laser was attenuated with an acousto-optical tunable filter, reflected by a dichroic mirror (main beam splitter HFT458) and focused by a Zeiss Plan-Neofluar $40 \times / 1.3$ NA Oil Dic objective onto the sample. The emitted fluorescent light was split by a second dichroic mirror (secondary beam splitter NFT515) into 2 separate channels, a 470-500 nm band-pass (CFP channel) and a 530- nm long-pass (YFP channel). For intracellular measurements, the desired measurement position was chosen in the LSM image. Cleavage of Bid was monitored by proteolytical FRET-disruption of a fusion protein YFP-Bid-CFP.

To quantify the results, the images were analyzed with Zeiss Rel3.2 image processing software (Zeiss, Germany) by drawing regions around individual cells and obtaining the average fluorescence intensity of YFP and CFP in each region for each image in the time series. YFP/CFP emission ratios were obtained by dividing the average fluorescence intensity values of single cells after background subtraction. For direct comparisons, the YFP/CFP ratio at the first time point was normalized to 1 .

\section{Spectrofluorometric analysis of Bid cleavage}

ASTC-a-1 cells stably expressing YFP-Bid-CFP were grown in DMEM supplemented with $15 \%$ FCS for $72 \mathrm{hr}$. Then, different groups of cells were treated with cisplatin, cisplatin plus calpeptin, cisplatin plus Z-IETD-fmk, or cisplatin plus Z-VAD-fmk, for $8 \mathrm{hr}$. After treatment, each group of the cells was transferred into a quartz cuvette, which was then placed inside the sample holder of a luminescence spectrometer (LS55, Perkin-Elmer). The fluorescence emission spectra were obtained with a luminescence spectrometer and the spectrum scanning analysis was performed 8-hr post-treatment. The excitation wavelength was $434 \pm 5 \mathrm{~nm}$, the excitation slit was $10 \mathrm{~nm}$, the emission slit was $15 \mathrm{~nm}$ and the scanning speed was $200 \mathrm{~nm} / \mathrm{s}$. The corresponding background spectra of cell-free culture media were subtracted.

\section{Calpain, caspase-2, caspase- 3 and caspase- 8 activity assays}

The activities of calpain, caspase- 8 , caspase- 2 and caspase- 3 were measured using the following fluorogenic enzyme substrates: Ac-LLY-AFC (BioVision, Mountain View, CA), IETD-AFC, VDVAD-AFC and DEVD-AFC (Alexis Biochemicals, Coger, Paris, France), respectively. After the desired duration of different treatments, the cells were harvested at $1,200 \mathrm{~g}$ and lysed with extraction buffer provided by the manufacturer. Cell lysates were centrifuged at $10,000 \mathrm{~g}$ at $4^{\circ} \mathrm{C}$ for $10 \mathrm{~min}$ and the supernatants were collected. After incubation at $37^{\circ} \mathrm{C}$ for $1 \mathrm{hr}$, the samples were read in a fluorometer equipped with a 400 -nm excitation filter and a 505-nm emission filter. The enzyme activity was expressed as relative fluorescence units per milligram protein of protein. The arbitrary values were presented as the mean \pm S.D. of 3 experiments.

\section{Western blotting analysis}

After different treatment, the effects on Bid and caspase- 8 were studied by Western blotting analysis. Equal amounts of proteins were loaded on SDS/PAGE, transferred to nitro-cellulose membranes and blotted with primary antibodies reactive to Bid and caspase-8 (Cell Signaling Technology, MA) at a dilution of 1:1,000, followed by secondary antibodies, goat anti-rabbit conjugated to IRDye ${ }^{\mathrm{TM}_{8}} 800$ (Rockland Immunochemicals, Gilbertsville, PA) for Bid and goat anti-mouse conjugated to Alexa Fluor 680 (Invitrogen, Carlsbad, CA) for caspase-8. Detection was performed using the LI-COR Odyssey Scanning Infrared Fluorescence Imaging System (LI-COR, Lincoln, NE).

\section{Cell viability assays}

Cells were cultured in a 96-well microplate at a density of $5 \times$ $10^{3}$ cells/well. The cells were treated with cisplatin, cisplatin plus calpeptin, or cisplatin plus Z-IETD-fmk and their viability was assessed with cell counting kit-8 (CCK-8) (Dojindo Laboratories, Kumamoto, Japan) according to the manufacturer's instructions 8 , 12,16 and 20 -hr post-treatment. $\mathrm{OD}_{450}$, the absorbance value at 450 nm, was read with a 96-well plate reader (DG5032, Huadong, Nanjing, China), to determine the viability and proliferation of the cells. 


\section{RNA interference}

Bid suppression was accomplished using Bid short hairpin RNA (shRNA) constructs. To generate Bid knockdown plasmids, several annealed sets of oligonucleotides encoding short hairpin RNAs (shRNA) corresponding to different sequences in Bid coding region were cloned individually into pGPU6/GFP/Neo vector (GenePharma, Shanghai, China). The oligonucleotides for shRNA were synthesized as follows: 1, shBid-33:5'-CACCGGGATG AGTGCATCACAAATTCAAGAGATTTGTGATGCACTCATCC CTTTTTTG-3'; 2, shBid-486: 5'-CACCGCGCCGTCCTTGCT CCGTGATTCAAGAGATCACGGAGCAAGGACGGCGTTTTTT G-3'. 3, shBid-196: 5'-CACCGCTCCCGCTTGGGAAGAATATT CAAGAGATATTCTTCCCAAGCGGGAGTTTTTTG-3'. 3, shBid160: 5'-CACCGCGATGAGCTGCAGACTGATTTCAAGAGAAT CAGTCTGCAGCTCATCGTTTTTTG- ${ }^{\prime}$. The negative control shRNA (shNC) was also generated and the oligonucleotides sequences were as follows: 5'-CACCGTTCTCCGAACGTGTCACGT CAAGAGATTACGTGACACGTTCGGAGA ATTTTTTG-3'.

\section{Bid-CFP translocation assay}

ASTC-a-1 cells were transiently cotransfected with Bid-CFP (a generous gift from Dr. K. Taira of University of Tokyo, Tokyo, Japan) and DsRed-Mit (a generous gift from Dr. Y. Gotoh of University of Tokyo, Tokyo, Japan). Thirty-six hours after transfection, cells were treated by cisplatin, cisplatin plus calpeptin, cisplatin plus Z-IETD-fmk, or cisplatin plus Z-VAD-fmk. Live cell imaging was performed by the Zeiss LSM 510 confocal microscope at $37^{\circ} \mathrm{C}$. The images of Bid-CFP and DsRed-Mit were obtained separately and then merged. The Bid-CFP localization in mitochondria was determined based on the overlap of Bid-CFP and DsRed-Mit fluorescence images.

\section{Cytochrome c release assays in Vitro}

Cytochrome $c$ release assays by Western blot were performed as described. ${ }^{37}$ Briefly, Cells were harvested, resuspended in 2 pellet volumes of lysis buffer [ $80 \mathrm{mM} \mathrm{KCl}, 250 \mathrm{mM}$ sucrose and $50 \mu \mathrm{g}$ / $\mathrm{ml}$ digitonin (Sigma-Aldrich, St. Louis, MO), $1 \mathrm{mM}$ DTT and Protease Inhibitor Cocktail Set I (Calbiochem, San Diego, CA)] and placed on ice for $10 \mathrm{~min}$. Samples were centrifuged at $10,000 \mathrm{~g}$ for $5 \mathrm{~min}$ and cytosols were transferred to new tubes. The pellet was resuspended in wash buffer $(20 \mathrm{mM}$ Hepes-KOH and $250 \mathrm{mM}$ $\mathrm{KCl}$ ), centrifuged again, and the wash added to the respective cytosols. To extract mitochondrial proteins, the pellet was resuspended in lysis buffer, lysed by freeze/thaw and centrifuged at 20,000 $\mathrm{g}$ for $10 \mathrm{~min}$. The supernatant, containing mitochondrial proteins and the cytosols were analyzed by Western blot.

\section{Detection of cytochrome $\mathrm{c}$ release}

ASTC-a-1 cells were transiently cotransfected with DsRed-Mit and E-GFP-Cyt- $c$ (a generous gift from Dr. G. J. Gores of Center for Basic Research in Digestive Diseases, Molecular Medicine Program, Mayo Clinic, Rochester, Minnesota). Thirty-six hours after transfection, cells were treated by different agents and imaged by the Zeiss LSM 510 confocal microscope at $37^{\circ} \mathrm{C}$. The images of GFP-Cyt- $c$ and DsRed-Mit were obtained separately and then merged. The GFP-Cyt- $c$ released from mitochondria was

Figure 1 - Cisplatin-induced apoptosis in ASTC-a-1 cells. (a) Time course of cells after different treatments as indicated [Cisplatin $(20 \mu \mathrm{M})$, calpeptin $(10 \mu \mathrm{M})$, PD150606 $(20 \mu \mathrm{M})$, Z-IETD-fmk $(10 \mu \mathrm{M})$, Z-VDVAD-fmk $(100 \mu \mathrm{M})$, Z-DEVD-fmk $(25 \mu \mathrm{M})$ and ZVAD-fmk $(25 \mu \mathrm{M})]$. Experiments were repeated 3 times. Bar $=5 \mu \mathrm{m}$. (b) Viability of ASTC-a-1 cells, after different treatments as indicated, was assessed by the CCK-8 assays at different time points. Data represent the mean \pm SEM of 4 independent experiments. [Color figure can be viewed in the online issue, which is available at www. interscience.wiley.com.]
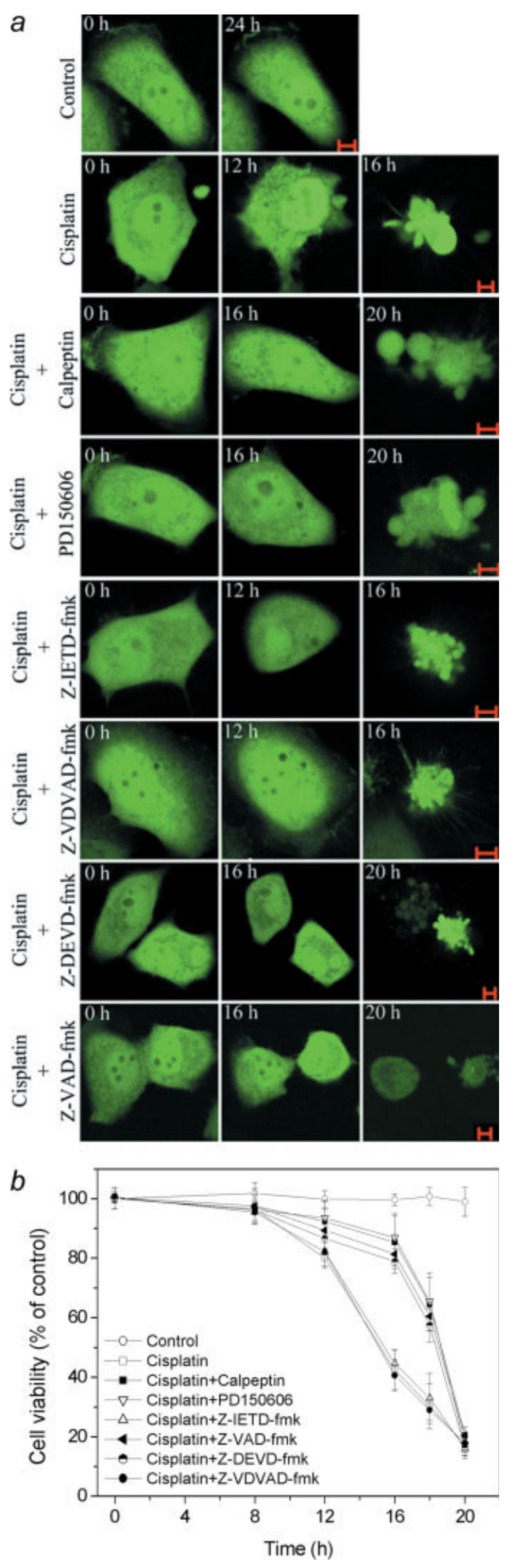

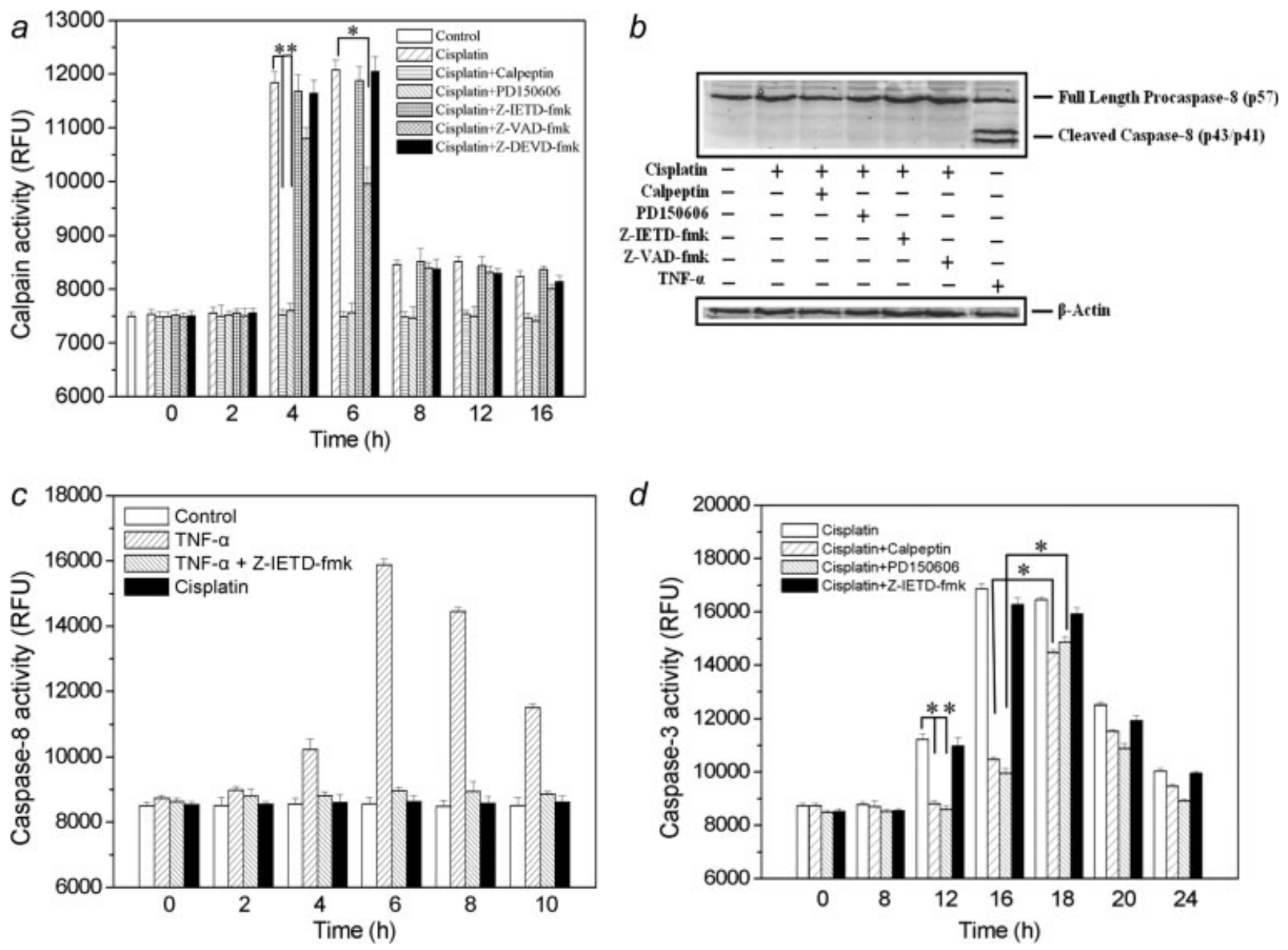

Figure 2 - Cisplatin induces the activation of calpain and caspase-3, but not caspase-8. (a) An increase in calpain activities induced by cisplatin. After different treatments as indicated, calpain activities, as assayed by the use of membrane-permeant fluorogenic calpain-specific substrate Ac-LLY-AFC at different time points, are indicated as relative fluorescence unit (RFU)/mg of protein and is expressed as arbitrary units determining the change in calpain activity, compared to untreated cells. (b) Western blot evidence that procaspase- 8 was not cleaved in cisplatin-induced apoptosis. Cells were treated as indicated and the effects on caspase- 8 were analyzed by Western blotting 12-hr post-treatment. The experiment with TNF- $\alpha$ treatment was used as a positive control. $\beta$-actin was used as a loading control. (c) Caspase- 8 activity was measured by assessing the fluorometric cleavage of IETD-AFC after treatment with cisplatin. The experiment with TNF- $\alpha$ treatment was used as a positive control. $(d)$ After different treatments as indicated, the induction of caspase-3 activity was measured by cleavage of the fluorogenic substrate DEVD-AFC (relative fluorescence units/mg of protein and expressed as arbitrary units). For all experiments, data represent the mean \pm S.D. of 3 independent experiments, $* p<0.05$.

determined based on the overlap of GFP-Cyt- $c$ and DsRed-Mit fluorescence images.

\section{Image processing and statistical analysis}

To quantify cells showing mitochondrial Bid-CFP, ASTC-a-1 cells cotransfected with Bid-CFP and DsRed-Mit were treated with different agents. At selected time points, the percentage of cells showing Bid translocation to mitochondria was assessed by counting the number of cells exhibiting mitochondrial Bid. Data were collected from $n=150-200$ cells per treatment in 10-15 randomly selected image frames from different experiments.

To quantify cells showing cytosolic GFP-Cyt-c, ASTC-a-1 cells cotransfected with GFP-Cyt- $c$ and DsRed-Mit were treated with different agents. At selected time points, the percentage of cells showing GFP-Cyt- $c$ released from mitochondria was assessed by counting the number of cells exhibiting cytosolic GFP-Cyt- $c$. Data were collected from $n=150-200$ cells per treatment in 10-15 randomly selected image frames from different experiments.

Data are represented as mean \pm SEM. Statistical analysis was performed with Student's paired $t$-test. Differences were considered statistically significant at $p<0.05$.

\section{Results}

\section{Cisplatin-induced apoptosis in ASTC-a-1 cells}

ASTC-a-1 cells were transfected transiently with GFP to label the morphology of intact cells. Control cells over-expressing GFP (Fig. 1 $a, 1$ st panel) were not impaired in their vitality, ruling out the possibility that ectopic expression of such protein is cytotoxic for this cell line.

To determine the role of calpain activation in cisplatin-induced apoptosis, cells expressing GFP were treated with cisplatin in the presence or absence of calpeptin or PD150606 (selective inhibitors of calpain). Figure $1 a$ (2nd panel) shows the typical hallmarks of apoptosis $16 \mathrm{hr}$ after cisplatin application. However, cell death was delayed by several hours when pretreated with calpeptin or PD150606 (Fig. 1a, 3rd and 4th panels).

It was observed that Z-IETD-fmk (selective inhibitor of caspase-8) did not alter the process of apoptosis (Fig. 1 $a$, 5th panel), indicating that caspase- 8 was not involved in the cisplatin-induced apoptotic pathway. Western blotting experiments and the enzymatic assay for caspase- 8 activity demonstrated that caspase- 8 was not activated (Figs. $2 b$ and $2 c$ ). However, significant protection against cell death was observed by using Z-DEVD-fmk and Z-VAD-fmk [Figs. $1 a$ (7th and 8th panels) and $1 b$ ]. Furthermore, 

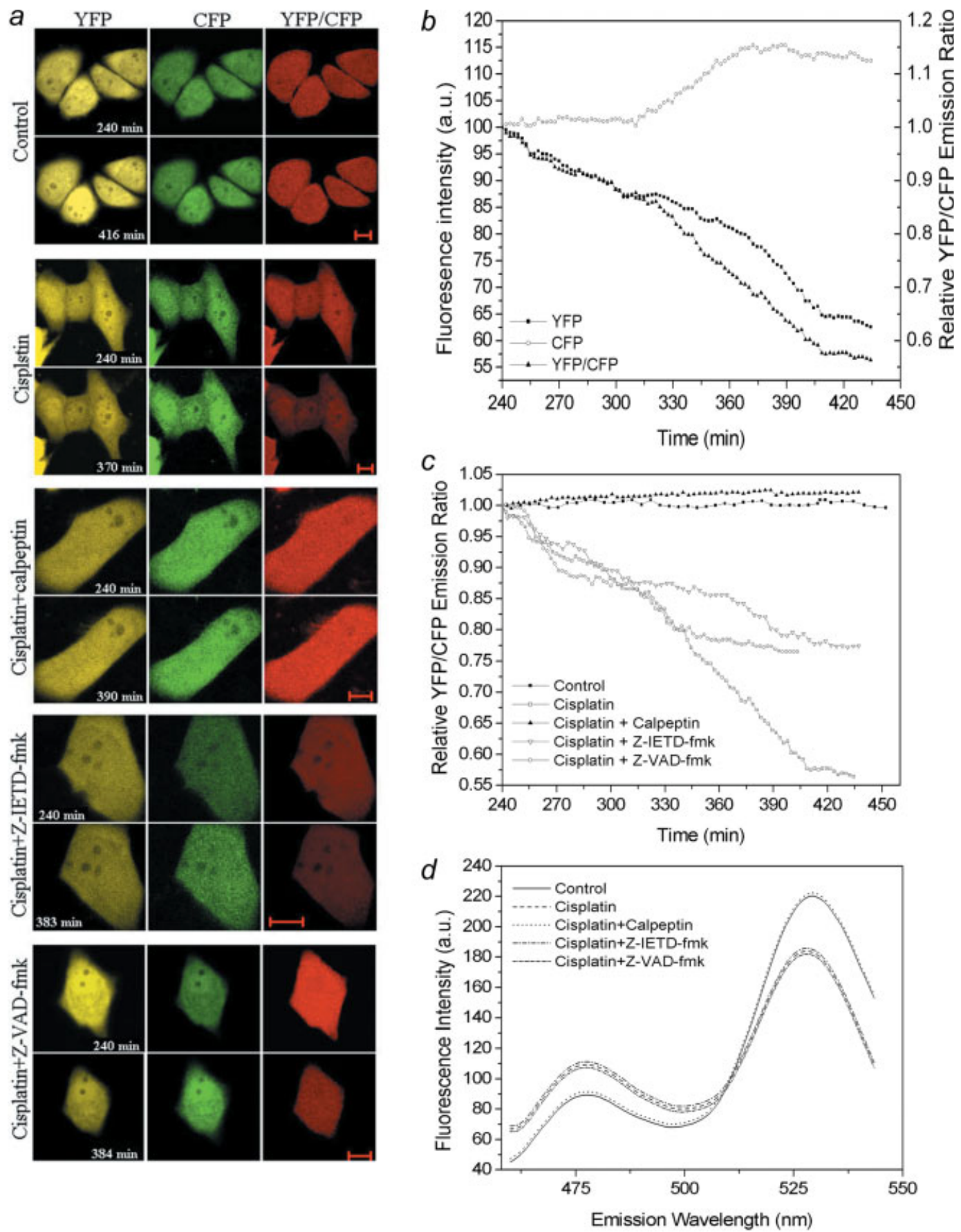

e

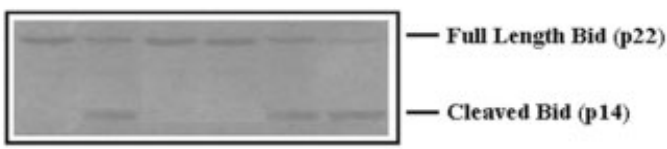

Cisplatin -+++++

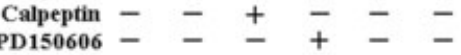

Z-IETD-fmk - - - - + -

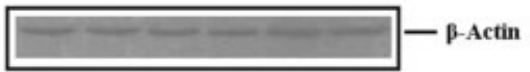

Figure 3. 
the analysis of the cleavage of the caspase- 3 substrate (Ac-DEVDAFC), induced by cisplatin, indicated an increase in caspase-3 activity. These data demonstrate that caspase-3 was involved in this experimental model. Interestingly, the activation of caspase-3 could be significantly inhibited and delayed by several hours when pretreated with calpeptin or PD150606 (Fig. 2d), indicating that activation of calpain proceeds that of caspase- 3 .

We observed the cell viability in ASTC-a-1 cells, using CCK-8 assay at different time points post-treatment. The viability of the cells after different treatments as indicated is shown in Figure $1 b$. The same results were obtained in A549 cells (data not shown). These results are consistent with our findings from fluorescence imaging.

\section{Cisplatin induces calpain activation}

ASTC-a-1 cells were treated as indicated in Figure $2 a$. At different time points post-treatment, calpain activity was assessed using the Calpain Activity Assay Kit. As shown in Figure $2 a$, cisplatin treatment for $2 \mathrm{hr}$ did not yield calpain activation, while a sharply increase was observed at 4-6 hr and the activity then decreased. In these assays, calpain activation was blocked by cotreatment with calpain inhibitor calpeptin. PD150606, another calpain-specific inhibitor, also blocked calpain activation. However, compared to treatment results by cisplatin along, cotreatment with Z-IETD-fmk or Z-VAD-fmk had no major effect on calpain activation; while Z-VAD-fmk decreased its activation (Fig. 2a).

\section{Real-time monitoring of calpain-mediated Bid cleavage induced by cisplatin}

FRET was applied to monitor Bid cleavage in cisplatin-induced apoptosis. ASTC-a-1 cells expressing YFP-Bid-CFP were treated as indicated in Figure $3 a$. The first image of each experiment was obtained 4-hr post-treatment. The typical time-course images of YFP and CFP are shown in Figure $3 a$. The control cells (1st panel) show no change during the recording time. After treatment with cisplatin, Bid cleavage was indicated by increased emission in the CFP channel and decreased emission in the YFP channel (Fig. $3 a$, 2nd panel); the same FRET is confirmed by quantitative analysis of fluorescence intensities (Fig. 3b). In the presence of calpeptin, the fluorescence intensities of YFP, CFP and YFP/CFP remained unchanged [Figs. $3 a$ (3rd panel) and $3 c$ ], indicating that the cleavage of Bid was blocked by inhibiting the activation of calpain. In the samples treated with cisplatin plus Z-VAD-fmk and cisplatin plus Z-IETD-fmk, the fluorescence images show the same FRET [Figs. $3 a$ (4th and 5th panels) and $3 c$ ] as that in cells treated by cisplatin along, indicating that Z-VAD-fmk and Z-IETD-fmk did not prevent Bid cleavage, thus excluding caspases-8, -3 and -2 from having any major role in Bid cleavage. These results were also confirmed by western blotting analysis (Fig. 3e).

Spectrofluorometric analysis of Bid cleavage induced by cisplatin

Shown in Figure $3 d$ are the results of spectrofluorometric analysis of the cleavage of YFP-Bid-CFP $8 \mathrm{hr}$ after treatment of ASTCa-1 cells stably expressing YFP-Bid-CFP. Cisplatin treatment resulted in a decrease in FRET-the emission peak of CFP
$(476 \mathrm{~nm})$ increased, while the emission peak of YFP $(527 \mathrm{~nm})$ decreased, indicating Bid cleavage. Similar results were obtained from the samples treated with cisplatin in the presence of Z-IETDfmk or Z-VAD-fmk. However, as shown in Figure 3d, FRET did not decrease in the samples cotreated with cisplatin and calpeptin. Furthermore, the time course of the emission spectrum of the cells cotreated by cisplatin and calpeptin was measured up to $12-\mathrm{hr}$ post-treatment and the results show no decrease in FRET (data not shown), indicating that Bid was not cleaved.

\section{Real-time detection of Bid translocation induced by cisplatin}

To observe the dynamic translocation of Bid to mitochondria after being cleaved by calpain during cisplatin-induced apoptosis in ASTC-a-1 cells, we utilized the Bid-CFP fusion protein to follow Bid migration with fluorescence imaging. Cells were transfected transiently by DsRed-Mit to label the mitochondria. After transfection, the cells were incubated for $36 \mathrm{hr}$, followed by different treatments of cisplatin, cisplatin and calpeptin, cisplatin and ZIETD-fmk, or cisplatin and Z-VAD-fmk. The real-time monitoring of Bid translocation was performed with the laser scanning microscope. The first image of each experiment was obtained 5-hr post-treatment and the distributions of Bid-CFP and DsRed-Mit were continuously recorded.

Typical images of real-time distribution of Bid-CFP in control nonapoptotic cells are shown in Figure 4a; Bid-CFP had a diffuse distribution throughout the cytoplasm, with little or no evident association with mitochondria for more than $9 \mathrm{hr}$. Figure $4 b$ shows the representative spatial and temporal relationships of Bid-CFP and DsRed-Mit after treatment with cisplatin; Bid-CFP displayed a diffuse and cytoplasmic localization 5-hr post-treatment, while at about 6.5 -hr post-treatment Bid-CFP partially translocated to mitochondria from cytoplasm as revealed by the overlaps of the Bid-CFP and DsRed-Mit fluorescence images. The majority of Bid-CFP localized at mitochondria $7 \mathrm{hr} 45 \mathrm{~min}$ post-treatment, as confirmed by the overlay image (Fig. $4 b$ ).

The dependence of Bid translocation on calpain and caspases was investigated. As shown in Figure $4 c$, we failed to detect BidCFP translocation to mitochondria $9 \mathrm{hr}$ after treatment with cisplatin-calpeptin. These results show that inhibiting the activation of calpain by calpeptin not only blocked cleavage of Bid, but also blocked its translocation to mitochondria. In contrast, neither ZIETD-fmk nor Z-VAD-fmk potently inhibited the redistribution of Bid-CFP from the cytoplasm to the mitochondria (Figs. $4 d$ and $4 e$ ). Quantitative analyses of time-dependent redistribution of BidCFP (Figs. $4 f$ and $4 g$ ) confirmed these findings. Quantitative analysis also revealed that Bid-CFP redistribution began nearly at the same time point as in cells treated by cisplatin, cisplatin and ZIETD-fmk, or cisplatin and Z-VAD-fmk (Fig. 4f).

\section{Real-time detection of cytochrome c release induced by cisplatin}

GFP-Cyt- $c$ was used to monitor the dynamic redistribution of cytochrome $c$. Using the confocal microscope operated under the 2-channel measurement mode, we imaged both the distribution pattern of GFP-Cyt- $c$ and that of DsRed-Mit simultaneously. The

FigURE 3 - Calpain-mediated Bid cleavage induced by Cisplatin. $(a-c)$ Dynamics of Bid cleavage in response to calpain activation during cisplatin-induced apoptosis in ASTC-a-1 cells transfected with YFP-Bid-CFP. (a) Fluorescence image series of CFP and YFP emissions of the cells after different treatments as indicated. The panels of CFP, YFP and YFP/CFP are shown separately. Bar, $10 \mu \mathrm{m}$. (b) Dynamics of YFP and CFP emission intensities and YFP/CFP ratio after cisplatin treatment. The YFP and CFP emission intensities at the first time point are normalized to 100 and the YFP/CFP ratio at the first time point is normalized to 1. (c) Dynamics of YFP/CFP ratio after different treatments as indicated. The YFP/CFP ratios at the first time point are normalized to 1 . Results represent 1 of 4 replicates. $(d)$ Spectrofluorometric analysis of the cleavage of YFP-Bid-CFP induced by cisplatin. Emission spectra of YFP-Bid-CFP $8 \mathrm{hr}$ after different treatments as indicated. ASTC-a-1 cells stably expressing YFP-Bid-CFP were excited at the excitation wavelength of CFP $(434 \pm 5 \mathrm{~nm})$, resulting in a CFP emission peak (476 nm) and YFP emission peak $(527 \mathrm{~nm}$ ) caused by FRET from CFP for control cells and cells treated by cisplatin and calpeptin. The reduction in FRET (an increase in emission at $476 \mathrm{~nm}$ and a decrease in emission at $527 \mathrm{~nm}$ ) is observed in cells treated by cisplatin, cisplatin and Z-IETD-fmk or cisplatin and Z-VAD-fmk. Results represent 1 of 3 replicates. (e) Calpeptin-sensitive Bid cleavage induced by cisplatin. ASTC-a-1 cells were treated as indicated and the effects on Bid cleavage were analyzed by Western blotting 12-hr post-treatment. $\beta$-actin was used as a loading control. Results represent 1 of 3 replicates. [Color figure can be viewed in the online issue, which is available at www.interscience.wiley.com.] 

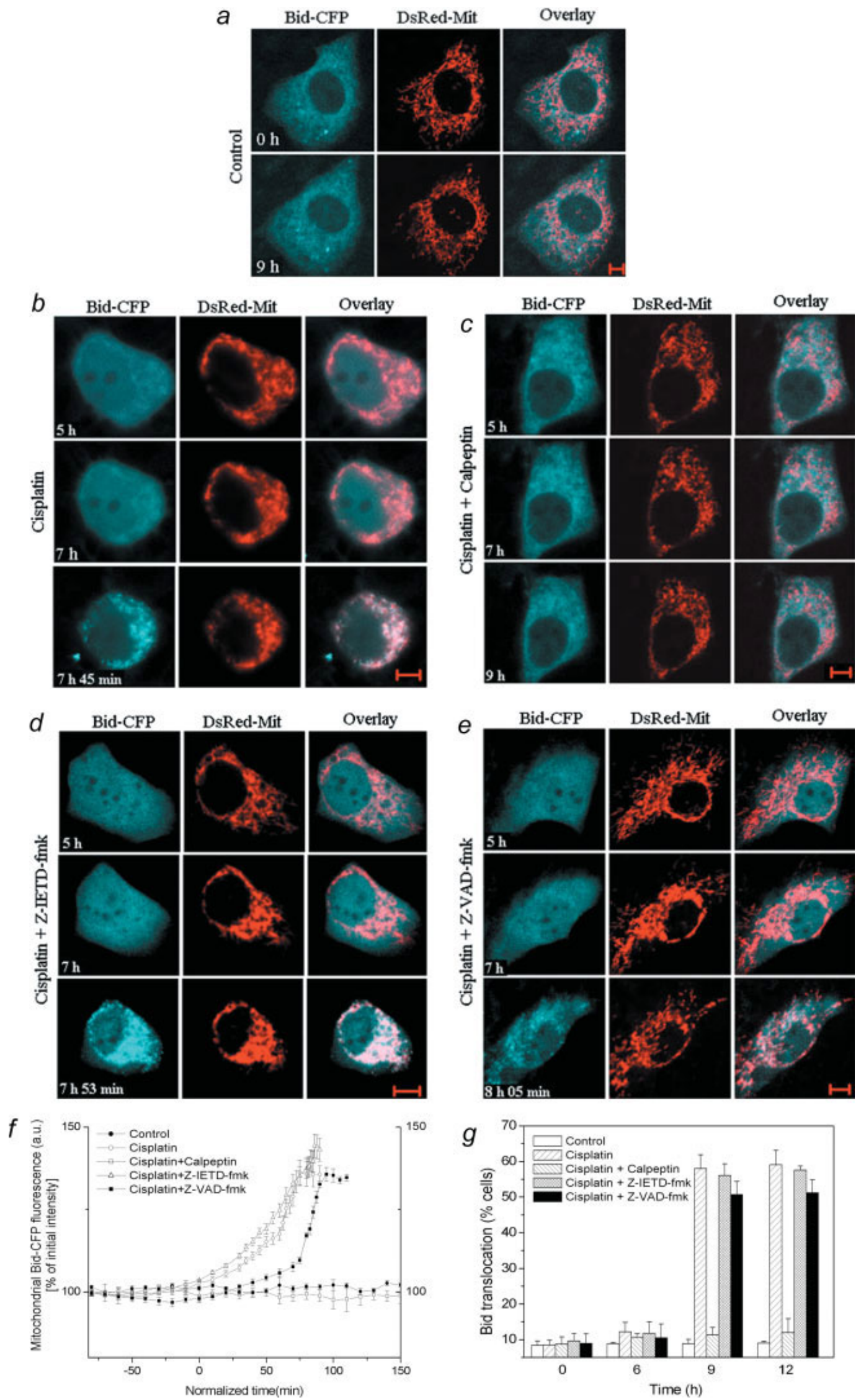

Figure 4. 
first image of each experiment was obtained 5-hr post-treatment and the distributions of cytochrome $c$ and DsRed-Mit at different times were recorded.

Before cytochrome $c$ release, the distribution patterns of both cytochrome $c$ and DsRed-Mit were the same as that of mitochondria, appearing as filamentous structures as shown in the control cell (Fig. $5 a$ ). Figure $5 b$ shows a typical record of real-time measurement, where the cell was undergoing cytochrome $c$ release after cisplatin treatment. As cytochrome $c$ was released from mitochondria about 8-hr post-treatment, the GFP-Cyt- $c$ in the cell became uniformly distributed over the entire cytoplasm (Fig. 5b).

Figure $5 c$ shows the typical time course of cytochrome $c$ release in the cells cotransfected with GFP-Cyt- $c$ and DsRed-Mit and cotreated with cisplatin and calpeptin. From the images we found that $8 \mathrm{hr}$ after treatment, none or little of the mitochondria released their cytochrome $c$. Judging by the overlap of GFP-Cyt- $c$ and DsRed-Mit fluorescence images (Fig. 5c), however, cytochrome $c$ was found being released from mitochondria about $10 \mathrm{hr}$ after the treatment. After another $30 \mathrm{~min}$, all mitochondria released their cytochrome $c$ and the GFP-Cyt- $c$ became diffusely distributed throughout the cytoplasm. These data suggest that calpeptin did not block cytochrome $c$ release completely, but only delayed its onset. Cells cotreated with cisplatin and PD150606 showed the same results (Fig. $5 d$ ).

The temporal relationship of cytochrome $c$ release in relation to the pretreatment of calpeptin or PD150606 was further delineated by a statistical analysis. The results in Figure $5 e$ show that the pretreatment of calpeptin or PD150606, while inhibiting the activation of calpain, did not prevent the release of cytochrome $c$ completely, but only delayed its onset.

\section{Suppressing Bid delays cytochrome c release and cell apoptosis}

Our experiments demonstrated that Bid is the critical calpain substrate in the study model, then we raised the question of whether down-regulation or knock-out of Bid should have the same effect of calpeptin. To address this, we used RNAi to silence the expression of Bid. We designed 4 shRNAs, shBid-33, shBid-486, shBid-196 and shBid- 160 . The data shown that shBid-33 and shBid-486 significantly reduced endogenous Bid protein $(>80 \%)$ compared to negative control shNC, whereas shBid-196 and shBid-160 had less effect (Figs. $6 a$ and $6 b$ ). Silencing Bid by transient transfection of shBid33 or shBid-486 in ASTC-a-1 cells obviously delayed cytochrome $c$ release and cell death (Figs. $6 c$ and $6 d$ ). The same results were obtained in A549 cells (data not shown).

\section{Caspase-2 was not involved in cisplatin-induced} apoptosis in ASTC-a-1 cells

Considerable evidence indicates that caspase- 2 is activated early in response to a variety of apoptotic stimuli; it can permeabilize the OMM directly and stimulate the release of cytochrome $c$ and Smac/DIABLO from mitochondria independent of Bid, Bax or other cytosolic factors. ${ }^{38-41}$ Thus we studied the involvement of caspase-2 in cisplatin-induced apoptosis in human lung adenocar- cinoma cells. The enzymatic assay for caspase- 2 activity indicated that caspase-2 was not activated (Fig. 7a). The inhibition of caspase-2 activation by using Z-VDVAD-fmk (selective inhibitor of caspase-2) showed no effect on cytochrome $c$ and Smac/DIABLO release (Figs. $7 b$ and $7 c$ ) and cell death [Fig. $1 a$ (6th panel) and $1 b$ ] induced by cisplatin.

\section{Discussion}

Many reports have shown that apoptosis is a marker of tumor cells exposed to cisplatin. ${ }^{1,2}$ However, the mechanisms of cisplatinmediated apoptosis are not fully understood. Considerable evidence has indicated that factors such as p53, calpain, Bcl-2 family, caspases, CD95 and IAPs may influence the ability of cisplatin to induce apoptosis. $2,11,42-44$

Possible involvement of calpain in apoptosis was first suggested in $1993 .{ }^{45}$ Involvement of calpain has been observed in response to irradiation, serum deprivation, staurosporine, etoposide and cisplatin. ${ }^{2,9,11,44}$ These studies suggest that calpain-mediated cleavage of Bcl-2 family proteins (Bax, Bid, Bcl-2 and Bcl-xL) results in conformational changes, hence their activation. ${ }^{11,27,46}$

The current study addresses several essential issues of cisplatininduced tumor cell apoptosis, including the dynamics of apoptotic process and the roles of calpain and caspases.

Apoptosis induced by cisplatin in human lung adenocarcinoma cells was studied using real-time single-cell analysis. Fluorescence images of tumor cells transfected by GFP (Fig. 1a, 2nd panel) clearly show cell apoptosis induced by cisplatin. After cisplatin treatment, calpain was activated (Fig. $2 a$ ), resulting in Bid cleavage at $4-5 \mathrm{hr}$, evidenced by the decrease of FRET [Figs. $3 a$ (2nd panel) and $3 b$, followed by Bid translocation (Figs. $4 b, 4 f$ and $4 g$ ), cytochrome $c$ release (Figs. $5 b$ and $5 e$ ) and caspase- 3 activation (Fig. $2 d$ ), leading to cell death.

To investigate the role of calpain activation in the induced apoptosis, cisplatin was coadministered with calpeptin or PD150606. Bid cleavage was blocked by the use of calpeptin, as shown by the stable FRET in Figures $3 a$ (3rd panel), $3 c$ and $3 d$. Figures $4 b, 4 d$ and $4 e$ vividly show the dynamics of Bid translocation to mitochondria, caused by the treatment of cisplatin, while images in Figure $4 c$ show undisturbed mitochondria in cells cotreated by cisplatin and calpeptin. Furthermore, the cytosolic GFP-Cyt-c fluorescence images of cells indicate that the use of calpeptin or PD150606 did not block cytochrome $c$ release (Figs. $5 c$ and $5 d$ ), but only delayed its onset (Figs. $5 c, 5 d$ and $5 e$ ), hence delaying caspase-3 activation (Fig. $2 d$ ) and cell death (Fig. 1). Our data demonstrated that Bid is the critical substrate of calpain in the study model, knock-down of Bid had the same effect on delaying cytochrome $c$ release and cell death compared to the calpeptin treatment (Figs. $6 c$ and $6 d$ ). These results suggest that cisplatin activates other signals in addition to the calpainmediated pathway. Previous studies have shown that p53 is a mediator in cisplatin-induced apoptotic pathways, ${ }^{1,2,43,47}$ which can initiate apoptosis by transcriptionally activating proapoptotic $\mathrm{Bcl}-2$ family members (e.g., Bax, Bak) or directly activating Bax. It is found that cisplatin-induced activation of the ER-specific caspase-12 resulted in

Figure 4 - Dynamics of Bid translocation to mitochondria during cisplatin-induced apoptosis. $(a-e)$ Typical time-lapse confocal images of living ASTC-a-1 cells transiently cotransfected with Bid-CFP and DsRed-Mit under different treatment conditions. The 2 panels of Bid-CFP and DsRed-Mit are shown separately and are merged to show the overlay. Bid-CFP localization at mitochondria was determined based on the overlap of Bid-CFP and DsRed-Mit fluorescence images. (a) Control cells without Bid translocation over time. (b) Time-lapse images of BidCFP redistribution after treatment with cisplatin. $(c)$ Time-lapse images of Bid-CFP redistribution after cotreatment with cisplatin and calpeptin. The overlay demonstrates that calpeptin inhibited Bid-CFP translocation. $(d)$ and $(e)$ Time-lapse images of Bid-CFP redistribution after cotreatment with cisplatin and Z-IETD-fmk and with cisplatin and Z-VAD-fmk, respectively. The overlay demonstrates that Z-IETD-fmk and Z-VADfmk did not inhibit Bid-CFP translocation. Similar results were obtained from 3 independent experiments. Bar, $10 \mu \mathrm{m}$. $(f)$ Time courses of Bid translocation to mitochondria after different treatments as indicated. Each curve represents an average of 12-15 cells obtained from 3 independent experiments. Bid-CFP fluorescence intensity in each curve at the first time point is normalized to 100 and the time of the onset of Bid-CFP redistribution is set to zero. Data represent the mean \pm SEM. ( $g$ ) Quantification of cells showing mitochondrial Bid-CFP. At indicated time points, the percentage of cells showing Bid translocation to mitochondria was assessed by counting the number of cells exhibiting mitochondrial Bid. Data were collected from $n=150-200$ cells per treatment in 10-15 randomly selected image frames from $n=3$ independent experiments. Data represent the mean \pm SEM. [Color figure can be viewed in the online issue, which is available at www.interscience.wiley.com.] 

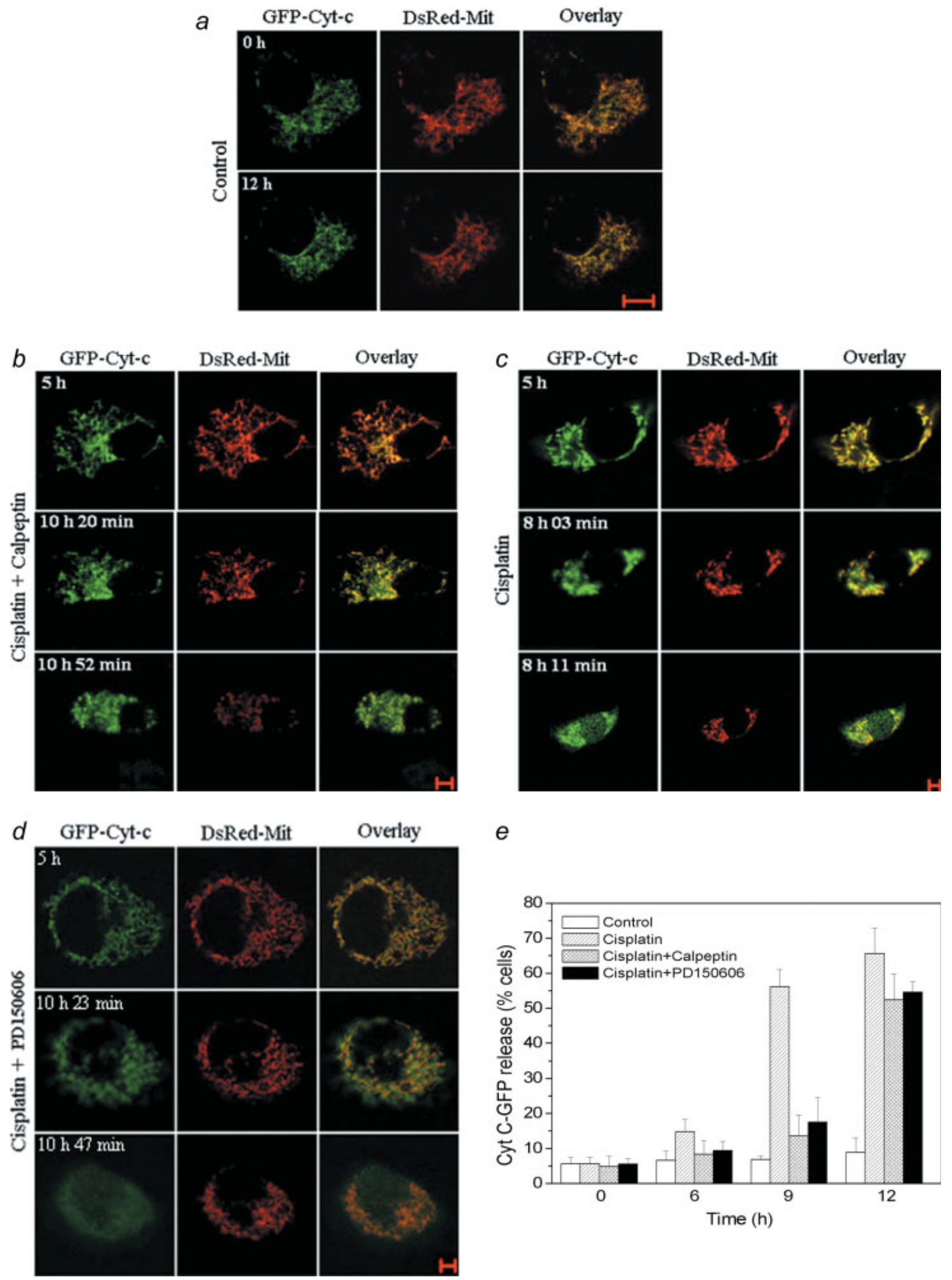

e

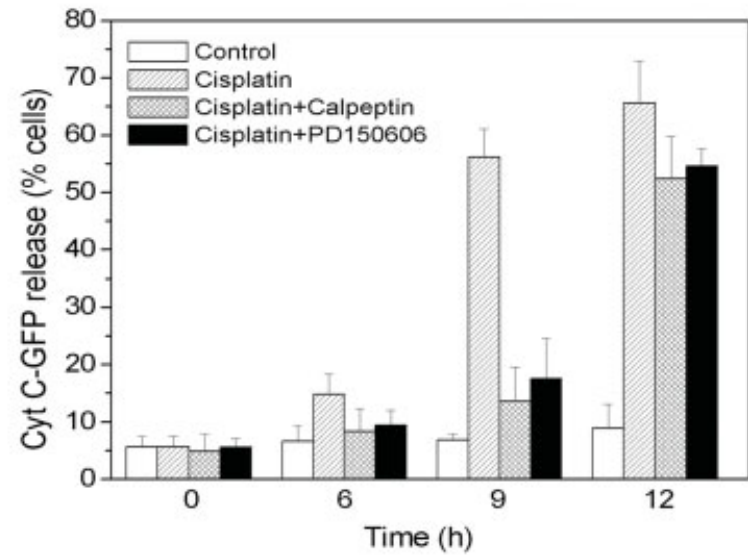

Figure 5 - Detection of cytochrome $c$ release from mitochondria during cisplatin-induced apoptosis. $(a-d)$ Typical time-lapse confocal images of living ASTC-a-1 cells transiently cotransfected with GFP-Cyt- $c$ and DsRed-Mit under different treatments. The 2 panels of GFP-Cyt$c$ and DsRed-Mit are shown separately and are merged to show the overlay. (a) Time-lapse images of GFP-Cyt- $c$ distribution in the cell without treatment. There is no sign of cytochrome $c$ release. $(b)$ Time-lapse images of GFP-Cyt $-c$ redistribution after treatment with cisplatin. The overlay demonstrates the GFP-Cyt- $c$ release from mitochondria about $8 \mathrm{hr}$ after treatment with cisplatin. (c) Time-lapse images of GFP-Cyt- $c$ redistribution after cotreatment with cisplatin and calpeptin. The overlay shows GFP-Cyt- $c$ release about $10 \mathrm{hr}$ after treatment with cisplatin, indicating that calpeptin cannot inhibit GFP-Cyt- $c$ release, but only delay its onset. $(d)$ Time-lapse images of GFP-Cyt- $c$ redistribution after cotreatment with cisplatin and PD150606. The result is the same as that shown in Figure $(c)$. Similar results were obtained from 3 independent experiments. Bar, $10 \mu \mathrm{m}$. (e) Quantification of cells showing cytosolic GFP-Cyt-c. At indicated time points, the percentage of cells showing GFP-Cyt- $c$ release from mitochondria was assessed by counting the number of cells exhibiting cytosolic GFP-Cyt- $c$. Data were collected from $n=150-200$ cells per treatment in 10-15 randomly selected image frames from $n=3$ independent experiments. [Color figure can be viewed in the online issue, which is available at www.interscience.wiley.com.] 

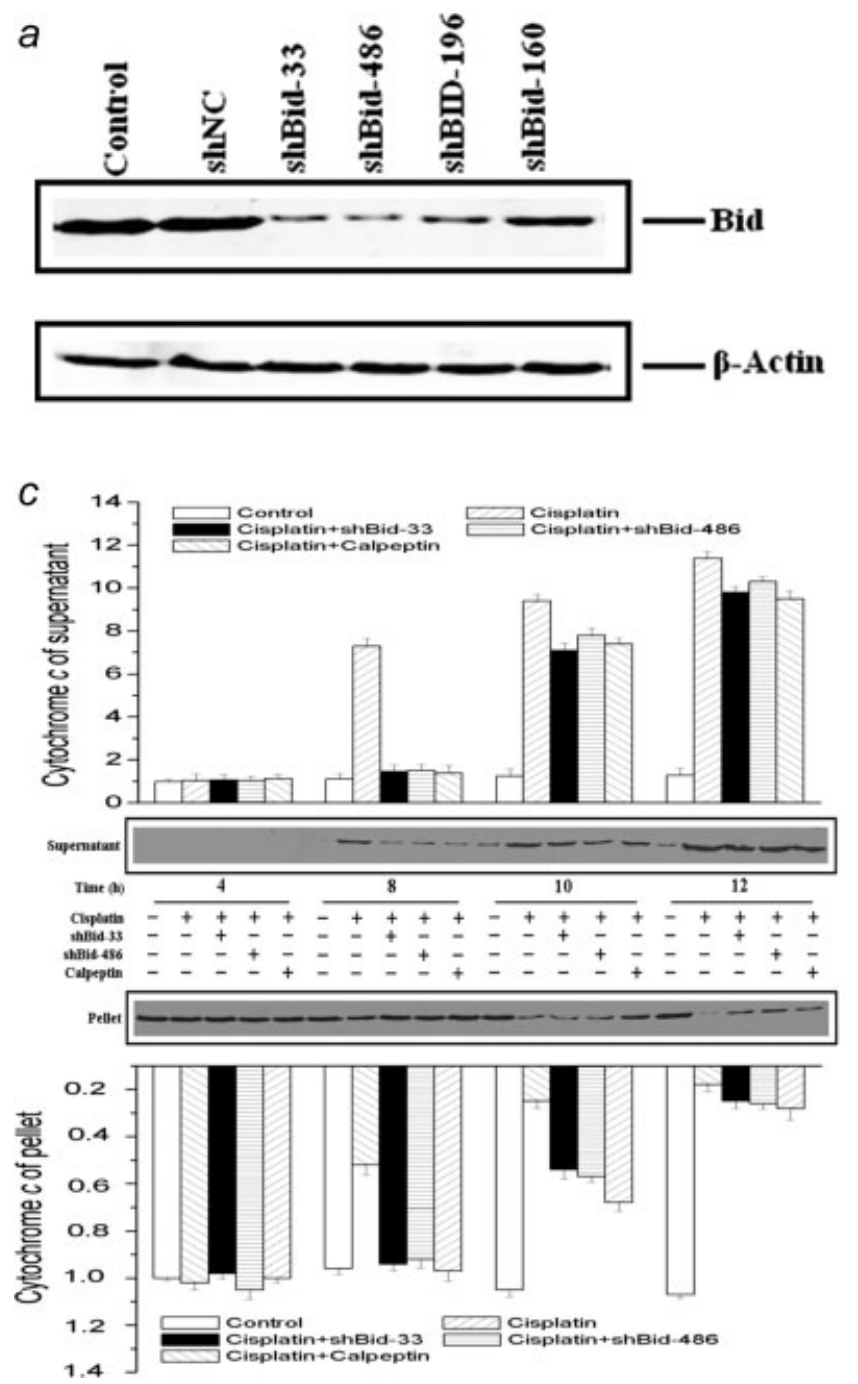

$b$
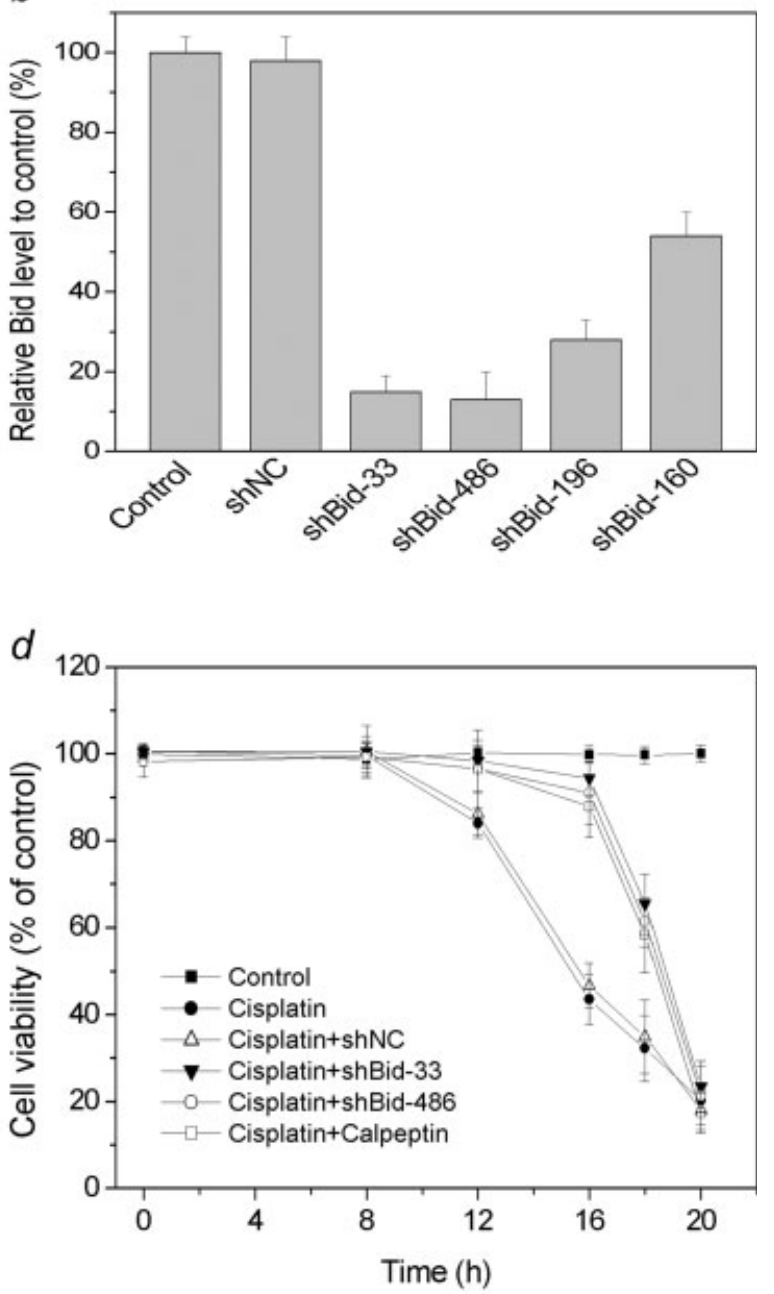

Figure 6 - Suppressing Bid delays cytochrome $c$ release and cell apoptosis. (a) ASTC-a-1 cells were transfected with the same amount of shBid-33, shBid-486, shBid-196, shBid-160 and cultured for $36 \mathrm{hr}$. The levels of endogenous Bid were assessed by immunoblotting. shNC was a negative control for shRNA. $\beta$-actin served as a loading control. (b) Interference effects of shRNAs on Bid expression. The amount of Bid in the culture medium was assayed $36 \mathrm{hr}$ after transfection. Data presented are means \pm SD of 3 independent transfection experiments and are plotted as a percentage of the control level. $(c)$ Knock-down of Bid delays cytochrome $c$ release induced by cisplatin. Cells were treated as indicated, harvested and then treated with digitonin. The cytosol and mitochondria (pellet) were analyzed by Western blot at different time points for the presence of cytochrome $c$. Densitometric results of 4 separate blots were used for quantitative analysis. For densitometry, values were normalized according to the control sample lanes that were arbitrarily set as 1. $(d)$ Down-regulation of Bid delays the cell death induced by cisplatin in ASTC-a-1 cells. The viability of cells after different treatments as indicated, was assessed by the CCK-8 assays at different time points. Data represent the mean \pm SEM of 4 independent experiments.

apoptosis. ${ }^{44}$ Other studies have demonstrated that extracellular signal-regulated kinases (ERK) can also be activated by cisplatin treatment in Hela cells. ${ }^{19}$ On the basis of our findings, the dominant mechanism of cisplatin-induced cell death is the calpain-mediated Bid cleavage and translocation. As for the delayed cell death after calpain is inhibited, the mechanism is not clear. We are currently investigating the additional apoptosis mechanism not requiring the Bid activities, such as p53-mediated apoptotic pathway.

The pathways involved in the cross-talk between the calpain and caspase proteolytic system remain controversial., ${ }^{9,48-51}$ For example, calpain-mediated N-terminal truncation of caspase- 3 to a p30 polypeptide enhanced caspase- 3 activation in one study ${ }^{52}$ and inhibited its activation in another, ${ }^{53}$ while Dursun et al. reported that caspases and calpain are independent mediators of cisplatininduced endothelial cell necrosis. ${ }^{54}$ In current study, the calpain inhibitors Calpeptin and PD150606 was found to obviously delay the activation of caspase-3 in cisplatin-induced apoptosis, which was associated with the delay of cytochrome $c$ release and cell death, suggesting that calpain activation proceeds the activation of caspase-3. Previous studies reported that caspase-3 can cleave the calpastatin, an endogenous calpain inhibitor, leading to loss of the inhibitory effect of calpastatin and to increase of calpain activation. ${ }^{48,55,56}$ However, in our study, calpain activity, which was inhibited significantly with calpeptin and PD150606, was unaffected by the caspase- 3 specific inhibitor (Fig. $2 a$ ), suggesting that caspase- 3 had no contribution to calpain activation.

Caspase- 8 has been shown to be the protease most responsible for Bid cleavage during death receptor-mediated apoptosis. ${ }^{13,25}$ However, the involvement of caspase-8 in cisplatin-induced apoptosis remains highly debated. ${ }^{11,17-20}$ We used caspase- 8 specific inhibitor Z-IETD-fmk with cisplatin in the treatment of tumor cells. Comparing the fluorescence images in Figure $1 a$ (2nd and 5th panel), it is evident that Z-IETD-fmk has no effect on apoptosis induced by cisplatin. The measured FRET (Fig. $3 a$, 4th panel), YFP and CFP emis- 

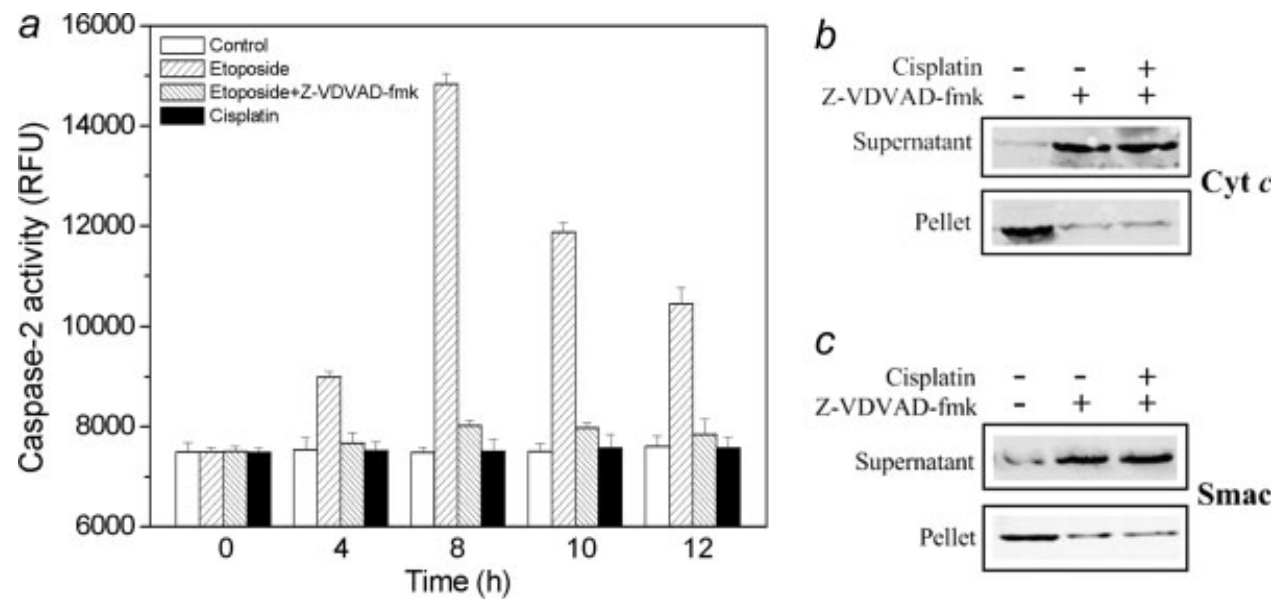

C

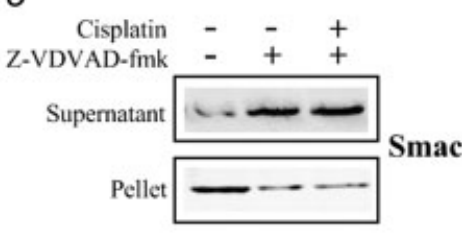

Figure 7 - Caspase-2 was not involved in cisplatin-induced apoptosis in ASTC-a-1 cells. (a) Activity assay demonstrates that caspase-2 was not activated. After different treatments as indicated, the induction of caspase- 2 activity was measured by cleavage of the fluorogenic substrate VDVAD-AFC (relative fluorescence units/mg of protein and expressed as arbitrary units). The experiment with Etoposide treatment was used as a positive control. Data represent the mean \pm S.D. of 4 independent experiments. $(b, c)$ Western blot experiments evidence that Z-VDVAD-fmk $(100 \mu \mathrm{M})$ did not inhibit the release of cytochrome $c(b)$ and Smac/DIABLO $(c)$ from mitochondria induced by cisplatin.

sions (Figs. $3 c$ and $3 d$ ), western blotting analysis (Fig. $3 e$ ), as well as cellular distribution of Bid-CFP (Fig. 4d) further indicate that ZIETD-fmk had no effect in Bid cleavage and Bid redistribution. Western blotting experiments and the enzymatic assay for caspase- 8 activity also demonstrated that caspase- 8 was not activated (Figs. $2 b$ and $2 c$ ). Therefore, our results excluded caspases- 8 from having any important role in cisplatin-induced apoptosis.

Interestingly, Z-VAD-fmk showed no major effects on Bid cleavage and translocation (Figs. $3 c, 3 d$ and $4 e$ ), but only slightly slowed the process of Bid-CFP translocation to mitochondria (Fig. $4 f$ ). The data suggest that Z-VAD-fmk is not a specific caspase inhibitor and can slightly inhibit calpain as shown in Figure $2 a$, which is consistent with the observations of previous studies. ${ }^{9}$ Further studies are needed to elucidate the mechanism.

Despite considerable evidence indicating that caspase- 2 is activated early in response to a variety of apoptotic stimuli, assigning a distinct function to this protease has been difficult. Recent findings indicate that caspase- 2 is an important initiator of the mitochondrial apoptosis pathway, which is required for the permeabilization of mitochondria and release of cytochrome $c$ and Smac/ DIABLO. ${ }^{38-41}$ Considering the number of pathways linking cytotoxic stress with mitochondrial engagement, it seems likely that the extent of caspase- 2 involvement depends on a number of factors, including the nature of the cytotoxic stimulus, the cell type that is being affected and the intracellular abundance of caspase-2 relative to that of other proapoptotic proteins. Indeed, experiments using caspase- 2 knockout mice, or cells in which caspase- 2 had been downregulated by antisense and siRNA approaches, as well as studies with caspase-2 inhibitors, suggested that caspase- 2 activation seems to be important for cell death in many, but not all, cell types. ${ }^{38-41}$ The results in our current study demonstrate that caspase-2 was not involved in the progression of cisplatin-induced apoptosis in human lung adenocarcinoma cells [Figs. 1a (6th panel), $1 b$ and 7], indicating that the role of caspase-2 in apoptosis is cell- and trigger-specific.

Bid plays an essential role in apoptosis. It has been established that Bid serves the unique function of interconnecting the extrinsic death receptors for TNF- $\alpha$ and Fas to the mitochondrial amplification loop of the intrinsic pathway. ${ }^{13,25}$ After TNF- $\alpha$ or Fas treatment, Bid is cleaved by caspase- 8 at Asp59 after the LQTD site, yielding a p15 C-terminal truncated fragment and exposing a new amino terminal Gly residue, which becomes myristoylated, facilitating Bid translocation to the mitochondria, where it induces the activation of $\mathrm{Bax}$ and $\mathrm{Bak}$, resulting in the release of cytochrome c. ${ }^{13,25,26,57}$ Therefore, the cleavage and redistribution of Bid has a profound effect on proapoptotic activity. Our data demonstrated that cleavage of Bid by calpain modulate cisplatin-induced apoptosis. However, it was reported that Bid was cleaved by calpain at Gly70 after the SRLG site, generating a p14 tBid and exposing an Arg residue, ${ }^{11}$ which is different from that cleaved by caspase- 8 . Therefore, posttranslational N-myristoylation of Bid may not explain the mechanism by which Bid translocates to mitochondria in the cisplatin-induced apoptotic pathway. How Bid rapidly and selectively targets the mitochondrial outer membrane should be further explored. It is possible that Bid can be activated by other forms of posttranslational modification such as phosphorylation. Alternatively, Bid may be regulated by proteins such as 14-3-3, which regulate the activity of another BH3-containing protein, Bad. ${ }^{58}$

According to our experimental data and related analysis, we demonstrated that cytochrome $c$ release and subsequent cell death caused by calpain activation appears to be the earliest action in cisplatin-induced apoptosis, as evidenced by the delay of cytochrome $c$ release (Figs. $5 c, 5 d$ and $5 e$ ) and subsequent delay of caspase- 3 activation (Fig. $2 d$ ) and cell death (Fig. 1) by the inhibitory effect of calpeptin or PD150606 or by knock-down of Bid (Figs. $6 c$ and $6 d$ ). Although detailed information on other pathways is not fully available, the delay of cytochrome $c$ release and subsequent delay of caspase- 3 activation and cell death by the inactivation of calpain exclude other earlier or parallel pathways, hence establishing the dominance of the calpain-mediated apoptotic pathway.

In conclusion, we demonstrated that calpain plays an important role in the cisplatin-induced apoptotic pathway. More importantly, our findings suggest that the calpain-mediated pathway is the kinetically earliest pathway, which may dominate the cisplatininduced apoptosis. Further studies are needed to determine how the calpain-mediated pathway interacts with other signal pathways. Our findings contribute to an improved understanding of the mechanisms involved in proapoptotic signaling mediated by cisplatin-based chemotherapy.

\section{Acknowledgements}

We thank Dr. K. Taira (University of Tokyo, Hongo, Tokyo, Japan) for kindly providing the pFRET-Bid and pBid-CFP plasmids, Dr. Y. Gotoh (University of Tokyo, Yayoi, Tokyo, Japan) for providing the pDsRed-Mit plasmid and we also thank Dr. G. J. Gores (Center for Basic Research in Digestive Diseases, Molecular Medicine Program, Mayo Clinic, Rochester Minnesota) for kindly providing the $\mathrm{pE}-\mathrm{GFP}-\mathrm{Cyt}-\mathrm{c}$ plasmid. 


\section{References}

1. Eastman A. The mechanism of action of cisplatin: from adducts to apoptosis. In: Lippert B, ed. Cisplatin, chemistry and biochemistry of a leading anticancer drug. Basel, Switzerland: Wiley-VCH, 1999. 11134.

2. Siddik ZH. Cisplatin: mode of cytotoxic action and molecular basis of resistance. Oncogene 2003;22:7265-79.

3. Jordan P, Carmo-Fonseca M. Cisplatin inhibits synthesis of ribosomal RNA in vivo. Nucleic Acids Res 1998;26:2831-6.

4. Salvesen GS, Dixit VM. Caspases: intracellular signaling by proteolysis. Cell 1997;91:443-6.

5. Thornberry NA, Lazebnik Y. Caspases: enemies within. Science 1998;281:1312-16.

6. Huang Y, Wang KKW. The calpain family and human disease. Trends Mol Med 2001;7:355-62.

7. Arthur SC, Elce JS, Hegadorn C, Williams K, Greer PA. Disruption of the murine calpain small subunit gene. Capn4: calpain is essential for embryonic development but not for cell growth and division. Mol Cell Biol 2000;20:4474-81.

8. Squier MK, Cohen JJ. Calpain, an upstream regulator of thymocyte apoptosis. J Immunol 1997; 158:3690-7.

9. Waterhouse NJ, Finucane DM, Green DR, Elce JS, Kumar S, Alnemri ES, Litwack G, Khanna K, Lavin MF, Watters DJ. Calpain activation is upstream of caspases in radiation-induced apoptosis. Cell Death Differ 1998;5:1051-61.

10. Kubbutat MHG, Vousden KH. Proteolytic cleavage of human p53 by calpain: a potential regulator of protein stability. Mol Cell Biol $1997 ; 17: 460-8$

11. Mandic A, Viktorsson K, Strandberg L, Heiden T, Hansson J, Linder $\mathrm{S}$, Shoshan MS. Calpain-mediated Bid cleavage and calpain-independent Bak modulation: two separate pathways in cisplatin-induced apoptosis. Mol Cell Biol 2002;22:3003-13.

12. Cryns V, Yuan J. Proteases to die for. Genes Dev 1998;12:155170.

13. Li H, Zhu H, Xu CJ, Yuan J. Cleavage of BID by caspase- 8 mediates the mitochondrial damage in the Fas pathway of apoptosis. Cell 1998;94:491-501.

14. Zou H, Li Y, Liu X, Wang X. An APAF-1 cytochrome c multimeric complex is a functional apoptosome that activates procaspase-9. J Biol Chem 1999;274:11549-56.

15. Green DR. Apoptotic pathways: ten minutes to dead. Cell 2005; 121:671-4.

16. Green DR Kroemer G. The pathophysiology of mitochondrial cell death. Science 2004;305:626-9.

17. Fulda S, Sieverts H, Friesen C, Herr I, Debatin KM. The CD95 (APO$1 /$ Fas) system mediates drug-induced apoptosis in neuroblastoma cells. Cancer Res 1997;57:3823-9.

18. Spierings DC, de Vries EG, Vellenga E, de Jong S. Loss of druginduced activation of the CD95 apoptotic pathway in a cisplatin-resistant testicular germ cell tumor cell line. Cell Death Differ 2003; 10:808-22.

19. Wang X, Martindale JL, Holbrook NJ. Requirement for ERK Activation in cisplatin-induced apoptosis. J Biol Chem 2000;275:39435-43.

20. Wang J, Ladrech S, Pujol R, Brabet P, Van De Water TR, Puel JL. Caspase inhibitors, but not c-Jun NH2-terminal kinase inhibitor treatment, prevent cisplatin-induced hearing loss. Cancer Res 2004;64: 9217-24.

21. Wang K, Yin XM, Chao DT, Milliman CL, Korsmeyer SJ. BID: a novel BH3 domain-only death agonist. Genes Dev 1996;10:285969.

22. Huang DCS, Strasser A. BH3-only proteins-essential initiators of apoptotic cell death. Cell 2000;103:839-42.

23. Green DR. At the gate of death. Cancer Cell 2006;9:328-30.

24. Korsmeyer SJ, Wei MC, Saito M, Weiler S, Oh KJ, Schlesinger PH. Pro-apoptotic cascade activates BID, which oligomerizes BAK or $\mathrm{BAX}$ into pores that result in the release of cytochrome c. Cell Death Differ 2000; 7:1166-73.

25. Luo X, Budihardjo I, Zou H, Slaughter C, Wang X. Bid, a Bcl-2 interacting protein, mediates cytochrome c release from mitochondria in response to activation of cell surface death receptors. Cell 1998; 94:481-90.

26. Wang $\mathrm{X}$. The expanding role of mitochondria in apoptosis. Genes Dev 2001;15:2922-33.

27. Chen M, He H, Zhan S, Krajewski S, Reed JC, Gottlieb RA. Bid is cleaved by calpain to an active fragment in vitro and during myocardial ischemia/reperfusion. J Biol Chem 2001;276:30724-8.

28. Vindis C, Elbaz M, Escargueil-Blanc I, Auge N, Heniquez A, Thiers JC, Salvayre AN, Salvayre R. Two distinct calcium-dependent mitochondrial pathways are involved in oxidized LDL-induced apoptosis. Arterioscler Thromb Vasc Biol 2005;25:639-45.

29. Slee EA, Keogh SA, Martin SJ. Cleavage of BID curing cytotoxic drug and UV radiation-induced apoptosis occurs downstream of the point of Bcl-2 action and is catalyzed by caspase-3: a potential feedback loop for amplification of apoptosis-associated mitochondrial cytochrome c release. Cell Death Differ 2000;7:556-65.

30. Orrenius S, Zhivotovsky B, Nicotera P. Regulation of cell death: the calcium-apoptosis link. Nat Rev Mol Cell Biol 2003;4:552-65.

31. Fields S, Song OK. A novel geneic system to detect protein-protein interactions. Nature 1989;340:245-46.

32. Sekar RB, Periasamy A. Fluorescence resonance energy transfer (FRET) microscopy imaging of live cell protein localizations. J Cell Biol 2003; 160:629-33.

33. Onuki R, Nagasaki A, Kawasaki H, Baba T, Uyeda TQP, Taira K. Confirmation by FRET in individual living cells of the absence of significant amyloid $\beta$-mediated caspase 8 activation. Proc Natl Acad Sci USA 2002;99:14716-21.

34. Zhang J, Campbell RE, Ting AY, Tsien RY. Creating new fluorescent probes for cell biology. Nat Rev Mol Cell Biol 2002;3:906-18.

35. Gao X, Chen T, Xing D, Wang F, Pei Y, Wei X. Single cell analysis of PKC activation during proliferation and apoptosis induced by laser irradiation. J Cell Physiol 2006;206:441-8.

36. Pei Y, Xing D, Gao X, Liu L, Chen T. Real-time monitoring full length Bid interacting with Bax during TNF- $\alpha$-induced apoptosis. Apoptosis 2007; 12:1681-90.

37. Pagliari LJ, Kuwana T, Bonzon C, Newmeyer DD, Tu S, Beere HM, Green DR. The multidomain proapoptotic molecules Bax and Bak are directly activated by heat. Proc Natl Acad Sci USA 2005;102:1797580 .

38. Lassus P, Opitz-Araya X, Lazebnik Y. Requirement for caspase-2 in stress-induced apoptosis before mitochondrial permeabilization. Science 2002;297:1352-4.

39. Robertson JD, Enoksson M, Suomela M, Zhivotovsky B, Orrenius S. Caspase-2 acts upstream of mitochondria to promote cytochrome c release during etoposide-induced apoptosis. J Biol Chem 2002;277: 29803-9.

40. Guo Y, Srinivasula SM, Druilhe A, Fernandes-Alnemri T, Alnemri ES. Caspase-2 induces apoptosis by releasing proapoptotic proteins from mitochondria. J Biol Chem 2002;277:13430-7.

41. Robertson JD, Gogvadze V, Kropotov A, Vakifahmetoglu H, Zhivotovsky B, Orrenius S. Processed caspase-2 can induce mitochondriamediated apoptosis independently of its enzymatic activity. EMBO Rep 2004;5:643-8.

42. Kharbanda S, Ren R, Pandey P, Shafman TD, Feller SM, Weichselbaum RR, Kufe DW. Activation of the c-Abl tyrosine kinase in the stress response to DNA-damaging agents. Nature 1995;376:785-

43. Johnstone RW, Ruefli AA, Lowe SW. Apoptosis: a link between cancer genetics and chemotherapy. Cell 2002;108:153-64.

44. Mandic A, Hansson J, Linder S, Maria CS. Cisplatin induces endoplasmic reticulum stress and nucleus-independent apoptotic signaling. J Biol Chem 2003;278:9100-6.

45. Sarin A, Adams DH, Henkart PA. Protease inhibitors selectively block T cell receptor-triggered programmed cell death in a murine T cell hybridoma and activated peripheral T cells. J Exp Med 1993; 178:1693-700

46. Gil-Parrado S, Fernandez-Montalvan A, Assfalg-Machleidt I, Popp O, Bestvater F, Holloschi A, Knoch TA, Auerswld EA, Welsh K, Reed JC, Fritz H, Fuentes-Prior P, et al. Ionomycin-activated calpain triggers apoptosis. J Biol Chem 2002;277:27217-26.

47. Chipuk JE, Kuwana T, Bouchier-Hayes L, Droin NM, Newmeyer DD, Schuler M, Green DR. Direct activation of Bax by p53 mediates mitochondrial membrane permeabilization and apoptosis. Science 2004;303:1010-14.

48. Neumar RW, Xu YA, Gada H, Guttmann RP, Siman R. Cross-talk between calpain and capase proteolytic systems during neuronal apoptosis. J Biol Chem 2003;278:14162-7.

49. Das A, Banik NL, Ray SK. Mechanism of apoptosis with the involvement of calpain and caspase cascades in human malignant neuroblastoma SH-SY5Y cells exposed to flavonoids. Int J Cancer 2006; 119:2575-85.

50. Bello BD, Moretti D, Gamberucci A, Maellaro E. Cross-talk between calpain and capase-3/-7 in cisplatin-induced apoptosis of melanoma cells: a major role of calpain inhibition in cell death protection and p53 status. Oncogene 2007;26:2717-26.

51. Rami A. Ischemic neuronal death in the rat hippocampus: the calpaincalpastatin-caspase hypothesis. Neurobiol Dis 2003;13:75-88.

52. Blomgren K, Zhu C, Wang X, Karlsson JO, Leverin AL, Bahr BA, Mallard C, Hagberg H. Synergistic activation of caspase-3 by $m$-calpain after neonatal hypoxia-ischemia: a mechanism of "pathological apoptosis." J Biol Chem 2001;276:10191-8.

53. McGinnis KM, Gnegy ME, Park YH, Mukerjee N, Wang KK. Procaspase- 3 and poly(ADP)ribose polymerase (PARP) are calpain substrates. Biochem Biophys Res Commun 1999;263:94-9. 
54. Dursun B, He Z, Somerset H, Oh DJ, Faubel S, Edelstein CL. Caspases and calpain are independent mediators of cisplatin-induced endothelial cell necrosis. Am J Physiol Renal Physiol 2006;291:F57887.

55. Han F, Shirasaki Y, Fukunaga K. 3-[2-[4-(3-Chloro-2-methylphenylmethyl)-1-piperazinyl] ethyl]-5,6-dimethoxy-1-(4-imidazolylmethyl)$1 \mathrm{H}$-indazole hihydrochloride 3.5 hydrate (DY-9760e) is neuroprotective in rat microsphere embolism: role of the cross-talk between calpain and caspase-3 through calpastatin. J Biol Chem 2006;317: $529-36$.
56. Rami A, Volkmann T, Agarwal R, Schoninger S, Nurnberger F, Saido TC, Winckler J. $\beta 2$-Adrenergic receptor responsiveness of the calpaincalpastatin system and attenuation of neuronal death in rat hippocampus after transient global ischemia. Neurosci Res 2003;47: 373-82.

57. Zha J, Weiler S, Oh KJ, Wei MC, Korsmeyer SJ. Posttranslational Nmyristoylation of BID as a molecular switch for targeting mitochondria and apoptosis. Science 2000;290:1761-5.

58. Zha J, Harada H, Yang E, Jockel J, Korsmeyer SJ. Serine phosphorylation of death agonist bad in response to survival factor results in binding to 14-3-3 not BCL-xl. Cell 1996;87:619-28. 